\title{
A implementação do estatuto de Roma no âmbito interno brasileiro ante as recentes movimentações no Tribunal Penal Internacional
}

Pablo Rodrigo Alflen da Silva ${ }^{1}$

\section{Resumo}

O artigo trata acerca da implementação do Estatuto de Roma no âmbito interno brasileiro diante das recentes movimentações no Tribunal Penal Internacional. Para tanto, utiliza-se um método fenomenológico, com base no qual procura-se seguir da teoria à práxis e vice-versa, visando analisar, sobretudo de forma crítica, a problemática acerca da implementação do Estatuto de Roma no Brasil. Em vista disso, é analisada, em primeiro lugar, a necessidade de implementação do Estatuto de Roma e seus fundamentos jurídico-políticos. Em segundo lugar, são analisados exemplos de esforços envidados em prol da implementação do Estatuto a nível internacional, bem como o fato do primeiro caso já ter sido encaminhado a julgamento pela Corte. Em terceiro lugar, analisam-se aspectos relativos a implementação no Brasil e a necessidade de maior celeridade neste procedimento. A partir do estudo desenvolvido, observa-se que após quase sete anos da ratificação do Estatuto de Roma o Brasil ainda não procedeu à sua implementação, mas, apesar disso, elaborou projeto de lei de implementação, manifestando seu real interesse em promover a cooperação com a Corte e cumprir seu compromisso assumido perante a comunidade internacional.

Palavras-chave: Estatuto de Roma. Tribunal Penal Internacional. Implementação no Brasil.

\footnotetext{
${ }^{1}$ Professor de Direito Penal e Processual Penal a UNIVATES e do Curso de Especialização de Direito Penal e Política Criminal da UFRGS. Doutorando e mestre em Ciências Criminais pela PUCRS, Pesquisador credenciado ao CNPq. Instrutor do Tribunal de Ética e Disciplina da OABRS. Advogado Criminal. pabloalflen@pq.cnpq.br
} 


\section{Introdução}

Desde a primeira metade do século XX já se defendia o entendimento de que o estabelecimento da responsabilidade internacional pessoal ${ }^{2}$ por crimes contra a humanidade (delicta juris gentium) poderia ser tão eficaz como a "responsabilidade nacional". Porém, ao mesmo tempo, criticava-se a existência de um Direito Penal Internacional face à inexistência de órgãos internacionais que aplicassem as normas penais, sendo que, a partir de então, a possibilidade de criação de um Tribunal Penal Internacional passou a se apresentar como o grande tema da humanidade. A intensificação das relações internacionais após esse período culminou com os trabalhos políticos e as Conferências da ONU para a criação do Estatuto de Roma e o estabelecimento do Tribunal Penal Internacional.

A adesão de inúmeros Estados ao Estatuto de Fundação do Tribunal Penal Internacional (a seguir, “TPI”) gerou compromissos para eles no que diz respeito à contribuição com a Corte para a consecução do seu fim primário, qual seja, o combate à impunidade, particularmente, dos crimes mais graves na ordem internacional.

Contudo, juntamente com tais compromissos, surgiu a exigência relativa à implementação do Estatuto de Roma no âmbito interno dos Estados-Partes. A realização de tal processo de implementação tem se apresentado de forma mais célere em determinados Estados do que em outros, quer seja por fatores jurídicos internos, quer seja por fatores políticos.

Nesse sentido, propõe-se analisar, primeiramente, no que consiste o processo de implementação e de onde decorre a exigência de implementação das regras do Estatuto de Roma, para, em um segundo momento, analisar alguns exemplos de esforços envidados em prol da implementação do Estatuto de Roma e os fatores que conduziram a celeridade no processo de implementação. E, após

\footnotetext{
${ }^{2}$ Em 1946 Karl-Heinz Lüders analisou essa questão em relação aos crimes de guerra de acordo com a concepção predominante à época, segundo a qual tal crime contra o Direito Internacional não poderia ser cometido por indivíduos, senão somente por Estados, sendo que esse argumento encontrava apoio no Ordenamento Territorial de Guerra de Haia de 1907, em seu art. 3, alínea 2 (cf. LÜDERS, Strafgerichtsbarkeit über Angehörige des Feindstaats. Süddeutsche Juristen Zeitung, v. 1, n. 8/9, p. 214 passim, 1946).
} 
Prismas: Dir., Pol. Publ. e Mundial., Brasília, v. 6, n. 2, p. 379-398, jul./dez. 2009

isso, verificar que a necessidade de proceder à implementação do Estatuto se intensifica com a entrada em funcionamento da Corte, sendo que, por fim, procede-se a um exame da implementação no âmbito brasileiro.

\section{A exigência de implementação do estatuto de Roma no âmbito interno dos estados-partes}

Em matéria de tratados internacionais, algumas expressões são de uso corrente, tais como, adoção, subscrição (assinatura), ratificação e internalização, posto que representam fases do processo de formação dos tratados. A expressão “implementação”, no entanto, apesar de ser utilizada na ordem internacional, especialmente em relação a tratados, passou a ser empregada com maior frequência no plano jurídico e político internacional por ocasião da instalação do Tribunal Penal Internacional ${ }^{3}$.

A implementação consiste em um processo de natureza jurídico-política que compreende a totalidade de medidas internas que devem ser tomadas para garantir que os Estados que se comprometeram com determinado organismo ou ator internacional, mediante a subscrição e subsequente ratificação de tratado internacional, estejam aptos a cumprir as regras nele estabelecidas e a cooperar com a consecução dos seus fins. Pode-se dizer, portanto, que consiste em uma parte do processo de internalização estabelecida de forma expressa ou tácita no Tratado.

\footnotetext{
${ }^{3}$ Veja ALVAREZ, Alejandro. The implementation of the ICC Statute in Argentina. Journal of Int ernational Criminal Justice, [S.1.], n. 5, p. 480-492, 2007; ademais, AMBOS, Kai. La implementación del Estatuto de la Corte Penal Internacional en Alemania. Revista Electrónica de Ciencia Penal y Criminologia, [S.1.], n. 7, p. 1-31, 2005; também WIRTH, Steffen. Germany's new international crimes code. Journal of International Criminal Justice, [S.1.], n. 1, p. 153 passim, 2003; YANG, Lijun. On the principle of complementarity in the Rome Statute of the International Criminal Court. Chinese Journal of International Law, [S.l.], v. 4, p. 123 passim, 2005, referindo "the principle of complementarity has impact on a State's implementation of international substantive criminal law"; igualmente DEGAN, VladimirDjuro. On the Source of International Criminal Law. Chinese Journal of International Law, n. 1, p. 79, 2005 referindo "Many additional agreements will be concluded in the implementation of the Rome Statute"; sobretudo SCHABAS, William. A canadian implementing legislation for the Rome Statute. In: Yearbook of International Humanitarian Law, Cambridge, v. 3 , p. 337,2000 .
} 
O Estatuto de Roma, isto é, o Tratado de fundação do TPI, que entrou em vigência em 01 de julho de 2002, satisfazendo o disposto no seu art. $126^{4}$, não estabelece nenhuma norma que determine expressamente a implementação, por meio da transposição de suas disposições ao plano interno dos Estados. ${ }^{5}$ No entanto, justamente em virtude disso, surge a questão acerca de que se é possível falar em implementação como decorrência exclusivamente da responsabilidade assumida pelos Estados. Em outras palavras: não havendo um mandato expresso no referido Estatuto que determine a implementação por parte dos Estados, é possível se falar em obrigatoriedade da implementação?

Por questão de política externa, no que diz respeito mais especificamente às relações internacionais, de fato, seria possível se falar que a ratificação e o subsequente depósito do instrumento de ratificação do Estatuto de per se conduziriam à observância dos fins à que se propõe este Tratado na ordem internacional. Para tanto, seria suficiente ter em vista que a concepção mesma do Estatuto está baseada na noção de que promover a investigação, processo e julgamento dos crimes mais graves que afetam o direito humanitário internacional corresponde aos próprios Estados ${ }^{6}$ e, portanto, a jurisdição do Tribunal Penal Internacional seria complementar a dos Estados. A partir daí, porém, sob outra perspectiva, se poderia afirmar que, numa ótica político-interna, a implementação representaria a melhor forma de fazer subsistir essa tarefa primária dos Estados-Partes.

Entretanto, somente sob o ponto de vista político (externo ou interno) não se teria uma base legitimante para a implementação. Com isso, é imprescindível encontrar o aspecto que legitima a necessidade de implementação, o qual somente pode ser encontrado sob a ótica jurídica. Nesse sentido, apesar de não haver regra expressa, tem-se que a exigência de implementação está implícita tanto em alguns dispositivos, como no próprio preâmbulo do Estatuto do TPI.

${ }^{4}$ YANG, Lijun. On the principle of complementarity in the Rome Statute of the International Criminal Court. Chinese Journal of International Law, [S.1.], v. 4, p. 121, 2005.

${ }^{5}$ Assim, WERLE, Gerhard; NERLICH, Volker. A punibilidade dos crimes de guerra de acordo com o direito alemão. In: SILVA, Pablo Rodrigo Alflen da (Org.). Tribunal Penal Internacional: aspectos fundamentais e o novo código penal internacional alemão. Porto Alegre: S. A. Fabris, 2004. p. 92.

${ }^{6}$ Assim KAUL, Hans-Peter. La Corte Penal Internacional. Diálogo Político, [S.1.], n. 3, p. 21, set. 2004. 
Assim, o parágrafo 10 do preâmbulo do Estatuto enfatiza que a jurisdição do TPI é complementar às jurisdições penais nacionais, de forma que, com isso, os Estados-Partes expressam sua vontade de garantir o julgamento nacional dos crimes internacionais 7 . Por outro lado, o art. 88 prevê expressamente o dever de cooperação, sob todas as formas, dos Estados-Partes com o Tribunal. ${ }^{8}$ Porém, mais especificamente, o art. 17 do Estatuto prevê o chamado princípio da complementariedade, o qual pressupõe que os Estados-Partes sejam capazes de proceder à investigação e de promover o procedimento criminal dos crimes previstos no Estatuto9. Esse dispositivo cria uma presunção em favor da atuação por parte dos Estados ${ }^{10}$, isso porque, como se sabe, o processo perante o TPI somente é admissível à medida que não seja possível no âmbito doméstico, quer seja porque o Estado não está disposto a iniciar ações penais, quer seja porque não está em condições de fazê-lo. Isso é muito bem expressado por Schabas, ao referir:

In addition, because the Statute is predicated on complementarity, by which States themselves are presumed to be responsible for prosecuting suspects found on their own territory, many must also bring their substantive criminal law into line, enacting the offences of genocide, crimes against humanity and war crimes as defined in the Statute and ensuring that their courts can exercise universal jurisdiction over these crimes. ${ }^{11}$

Todavia, a abertura das regras no tocante a esse aspecto encontra sua ratio essendi justamente na necessidade de adequação constitucional do Estatuto,

7 "[...] the International Criminal Court established under this Statute shall be complementary to national criminal jurisdictions".

8 "States Parties shall ensure that there are procedures available under their national law for all of the forms of co operation which are specified under this Part."

9 Assim, AMBOS, Kai. Internationales strafrecht, strafanwendungsrecht, völkerstrafrecht, europäisches strafrecht. München: Beck, 2006. p. 111; fundamental sobre o princípio YANG, Lijun. On the principle of complementarity in the Rome Statute of the International Criminal Court. Chinese Journal of International Law, [S.1.], v. 4, p. 121 et seq., 2005; ademais, KAUL, Hans-Peter. La Corte Penal Internacional. Diálogo Político, [S.l.], n. 3, p. 21, set. 2004.

${ }^{10}$ Cf. CASSESE, Antonio. The statute of the International Criminal Court: some preliminary reflections. European Journal of International Law, [S.1.], n. 10, p. 158, 1999.

${ }^{11}$ Cf. SCHABAS, William. An introduction to the international criminal court. Cambridge: Cambridge University, 2001. p. 19. 
resultando, assim, uma margem considerável de conformação. ${ }^{12}$ Disso resulta, nas palavras de Ambos, que "os Estados, no entanto, estão livres para se decidir entre uma implementação limitada ou completa"13. A solução mínima consistiria, portanto, na implementação por meio da introdução dos dispositivos processuais necessários para a cooperação e da ampliação do rol de crimes com a inclusão daqueles delitos jurisdicionados pelo TPI ${ }^{14}$.

Contudo, é mister ter em vista ainda justamente o fato de que o Tribunal Penal Internacional representa um marco na ordem internacional, posto que evidencia o entrelaçamento contínuo de atividades humanas, atuando como uma alavanca que produz mudança de conduta na direção de nosso padrão, ou seja, evidencia que as mesmas pressões operam na mesma direção, no sentido de produzir mudanças que transcendem os padrões de conduta e sentimentos. E como se poderá verificar em seguida (infra, 2$)$, agregando-se esse aspecto à responsabilidade decorrente do compromisso assumido na ordem internacional (fator políticoexterno), de cooperar com o Tribunal Penal Internacional (fator político-interno) na consecução dos seus fins e das disposições do próprio Estatuto (fator jurídico), alguns Estados têm procedido com maior celeridade à implementação.

\section{Alguns exemplos internacionais de esforços envidados em prol da implementação}

Em 11 de dezembro de 2000, a Alemanha ratificou o Estatuto do TPI. Porém, face à necessidade de implementação do Estatuto de Roma, já no momento de sua subscrição, efetuada em 09 de dezembro de 1998, o governo alemão manifestava a intenção de adaptar o Direito Penal alemão interno vigente às suas regras. E tendo em vista esse propósito, em outubro de 1999 o governo alemão designou um grupo de estudiosos para trabalhar na elaboração do projeto de lei para a transposição

\footnotetext{
${ }^{12}$ Assim AMBOS, Kai. Internationales strafrecht, strafanwendungsrecht, völkerstrafrecht, europäisches strafrecht. München: Beck, 2006. p. 111.

${ }^{13}$ Cf. AMBOS, Kai. Internationales strafrecht, strafanwendungsrecht, völkerstrafrecht, europäisches strafrecht. München: Beck, 2006. p. 111, “os Estados, no entanto, estão livres para se decidir entre uma implementação plena e limitada".

${ }^{14}$ Veja AMBOS, Kai. Internationales strafrecht, strafanwendungsrecht, völkerstrafrecht, europäisches strafrecht. München: Beck, 2006. p. 111.
} 
do Estatuto (a esse grupo pertenciam seis cientistas do âmbito do Direito Penal e do Direito Internacional: Andreas Zimmermann, Claus Kreß, Gerhard Werle, Horst Fischer, Kai Ambos e Thomas Weigend). Em maio de 2001, foi apresentado o "Projeto de Trabalho de uma Lei de Introdução ao Código Penal Internacional". Em face disso, em 30 de junho de 2002, justamente um dia antes da entrada em vigência do Estatuto do TPI, entrou em vigência o Código Penal Internacional alemão (Völkerstrafgesetzbuch) ${ }^{15}$, o qual contém as disposições penais que afetam a comunidade internacional como um todo, a saber: o genocídio, os crimes contra a humanidade e os crimes de guerra. Em realidade, o Código Penal Internacional alemão foi parte de um grande "pacote" de leis elaborado, visando à transposição do Estatuto de Roma. Com a Lei de transposição do Estatuto do TPI, publicada no BGBl. 2000, II, S. 1393, o legislador alemão criou os pressupostos para a entrada em vigência do Estatuto na Alemanha ${ }^{16}$, e com a modificação do Art. 16, alínea 2 da própria Lei Fundamental, assegurou que os nacionais alemães poderão ser submetidos ao TPI.

O projeto alemão apresentava originariamente quatro finalidades básicas: 1- possibilitar uma melhor compreensão dos crimes contra o Direito Internacional e preencher algumas lacunas; 2 - desenvolver um trabalho próprio de regulamentação, orientado pela ideia de clareza e aplicabilidade à práxis; 3- tendo em vista a complementaridade da persecução penal pelo TPI, orientar-se segundo a ideia de, na dúvida, assegurar a liberdade; 4- contribuir com a proteção do Direito Internacional Humanitário mediante a criação de um trabalho de regulamentação

${ }^{15}$ A versão portuguesa do Código Penal Internacional alemão (VStGB), elaborada por Pablo Rodrigo Alflen da Silva, encontra-se publicada em SILVA, Pablo Rodrigo Alflen da (Org.). Tribunal Penal Internacional: aspectos fundamentais e o novo código penal internacional alemão. Porto Alegre: S. A. Fabris, 2004. A tradução foi resultado do projeto de traduções do Código Penal Internacional Alemão, desenvolvido junto ao Max Planck Institut für ausländisches und internationales Strafrecht, sob coordenação do Prof. Dr. Kai Ambos (Göttingen), e está disponível, integralmente, no site MAX-PLANCK-INSTITUT FÜR AUSLÄNDISCHES UND INTERNATIONALES STRAFRECHT. Freiburg, 2009. Disponível em: <http://www.mpicc.de/ww/de/pub/ forschung/publikationen/ onlinepub.htm >. Acesso em: 30 jan. 2009.

${ }^{16}$ Cf. WERLE, Gerhard; JEßBERGER, Florian. Das Völkerstrafgesetzbuch. Juristenzeitung, n. 15/16, p. 725, 2002; para uma análise detalhada veja ainda AMBOS, Kai. La implementación del Estatuto de la Corte Penal Internacional en Alemania. Revista Electrónica de Ciencia Penal y Criminologia, [S.l.], n. 7, p. 1-31, 2005. 
nacional e contribuir com a propagação dele. ${ }^{17}$ Tais aspectos são representativos do interesse político da Alemanha na celeridade do processo de implementação, o qual assume duas vias: em primeiro lugar, porque, dessa forma, na qualidade de ator internacional, evidencia à comunidade internacional o seu propósito de contribuir com os fins do tratado e, em segundo, deixa claro que, sendo um dos primeiros Estados a proceder a implementação, fornecerá aos demais Estados uma primeira e originária interpretação dos preceitos do Estatuto, influenciando, portanto, o processo de implementação deles e, com isso, de certo modo, ressaltando seu papel como ator internacional. ${ }^{18}$

A título exemplificativo, pode-se mencionar ainda o modelo canadense. $\mathrm{O}$ Canadá ratificou o Estatuto de Roma em 07 de julho de 2000 e sua implementação se deu por meio do Crimes Against Humanity and War Crimes Act, de 29 de junho de 2000, que entrou em vigência em 23 de outubro de $2000^{19}$, portanto, antes mesmo da entrada em vigência do Estatuto de Roma. Considerado o primeiro país a implementar o Estatuto $^{20}$, o Canadá seguiu a mesma orientação que foi adotada pelo governo alemão, ao criar um corpus iuris próprio. Naturalmente, o fato de ser o primeiro Estado na ordem internacional a implementar o Estatuto não foi produto do acaso, posto que, sob a perspectiva político-internacional, o Canadá procura pautar sua atuação por sua autoidentidade como bom cidadão internacional e pelo desejo de reconhecimento como autoridade moral na categoria cidadania ${ }^{21}$, ou seja, sua atuação política como ator internacional é orientada por sua reputação.

${ }^{17}$ Cf. GEIGER, Hansjörg. Internationaler Strafgerichtshof und Aspekte eines neuen Völkerstrafgesetzbuches. In: Freundesgabe für Alfred Büllesbach. [S.l.:s.n.], 2002. p. 341.

${ }^{18}$ Isto fica evidente em KRESS, Claus. Versailles, Nuremberg: the Hague, Germany and International Criminal Law. The International Lawyer, [S.1.], v. 40, n. 1, p. 39, 2006, quando ressalta que "After a long period of skepticism dating back to Leipzig, hardened by the Nuremberg experience, Germany is now contributing in an active and principled manner to the emergence of a system of international criminal justice."

${ }^{19}$ CANADÁ. Crimes against humanity and war crimes act. Ottawa, 2000. Disponível em: <http://laws.justice.gc.ca/PDF/Statute/C/C-45.9.pdf>. Acesso em: 01 fev. 2009.

${ }^{20} \mathrm{Cf}$. SCHABAS, William. A canadian implementing legislation for the Rome Statute. Yearbook of International Humanitarian Law, Cambridge, v. 3, p. 337, 2000, que ressalta ainda que "in evitably, then, other states have looked to Canada for leadership in the adoption of domestic laws aimed at facilitating ratification of the Rome Statute".

${ }^{21}$ Cf. SCHABAS, William. A canadian implementing legislation for the Rome Statute. Yearbook of International Humanitarian Law, Cambridge, v. 3, p. 337, 2000. 
Por outro lado, diferentemente da orientação adotada pelo Canadá e Alemanha, na França, a lei de implementação (Loi n. 2002-268 du 26 février 2002²2) determinou tão só a alteração do Código de Processo Penal, com a inclusão, no Livro IV, de vários dispositivos de caráter procedimental que se aplicam aos crimes definidos no Estatuto de Roma ${ }^{23}$. A celeridade na implementação francesa, de forma completamente diversa dos Estados antes referidos, deu-se exclusivamente pela necessidade de assegurar o funcionamento eficaz do Tribunal e pela grande esperança depositada no Tribunal no combate aos crimes graves, o que, aliás, constituiu a principal motivação para aqueles que contribuíram com a sua instalação. ${ }^{24}$

Interessante ressaltar que nos Estados até aqui mencionados, não se optou por uma transposição pontual dos artigos do Estatuto do TPI. Contudo, em sentido contrário, pode-se fazer menção a Trinidad y Tobago que efetuou uma transposição pontual. Nesse caso, justamente o caráter extenso da lei de implementação (contendo 182 artigos) evidencia o engajamento do Estado na transposição das regras do Estatuto ao plano interno. Isso porque a lei de implementação de Trinidad y Tobago foi publicada em 24 de fevereiro de 2006, sendo que o Estado ratificou o Estatuto em 06 de abril de 1999.

Naturalmente, a atitude pioneira de Estados como Canadá e Alemanha, bem como a França (em que pese a sua implementação de caráter limitado), e o esforço legislativo de Trinidad y Tobago, envidado em prol de uma implementação completa em caráter pontual, são bastante significativos, tanto no tocante à responsabilidade assumida pelos Estados no que se refere à contribuição para com o TPI, quanto ao compromisso assumido mediante a subscrição e consequente ratificação do Estatuto de Roma relativo ao combate à impunidade dos crimes mais graves na

${ }^{22}$ FRANÇA. Loi n 2002-268 du 26 février 2002 relative à la coopération avec la Cour pénale international. Paris, 2002. Disponível em: <http://www.iccnow.org/documents/ FrenchImplementingLeg.pdf $>$. Acesso em: 01 fev. 2009.

${ }^{23} \mathrm{O}$ Ministério da Justiça da França preparou ainda um projeto de implementação do direito penal material que, no entanto, encontra-se em discussão; para uma ampla análise da problemática constitucional de implementação do Estatuto do TPI na França, compare TAVERNIER, Paul. Comment surmonter les obstacles constitutionnels à la ratification du Statut de Rome de la Cour Pénale Internationale. Revue Trimestrielle des Droits de L'Homme, Paris, n. 51, p. 545 et. seq., jul. 2002.

${ }^{24}$ Compare: LA LOI FRANÇAISE D’ADAPTATION. Rapport de position $\mathrm{n}^{\circ}$ 6, Cour Pénale Internationale, $\mathrm{n}^{\circ} 312$, Septembre 2001, ad. 1, p. 10. 
ordem internacional, sobretudo diante do encaminhamento do primeiro caso a julgamento pela Corte (infra, 3).

\section{Os primeiros casos perante o Tribunal Penal Internacional}

Após seu estabelecimento como Tribunal universal permanente de jurisdição penal, as expectativas acerca de sua atuação em observância aos seus fins, somente têm aumentado principalmente com o encaminhamento à Corte das primeiras situações, ocorridas em Darfur (Sudão), na África Central, em Uganda e na República Democrática do Congo, em que se cogitam a prática de crimes internacionais de competência do Tribunal.

Entretanto, as expectativas aumentam cada vez mais com as últimas manifestações que confirmam o encaminhamento ao primeiro julgamento. Isso porque, em 19 de abril de 2004, o governo da República Democrática do Congo ${ }^{25}$ remeteu formalmente ao Tribunal Penal Internacional a solicitação de providências ${ }^{26}$ no sentido de investigar se havia sido perpetrados em qualquer parte do território do Estado, crimes de competência do Tribunal, desde sua entrada em vigência, em 01 de julho de 2002. Após a realização das investigações, o Promotor requereu, em 13 de janeiro de 2006, a prisão de Thomas Lubanga Dyilo.

Lubanga, líder da União Patriótica Congolesa ${ }^{27}$, foi acusado dos seguintes crimes de guerra: 1) alistamento de crianças; 2) recrutamento de crianças como soldados; e 3) uso de crianças na participação ativa em hostilidades na República Democrática do Congo. Tais fatos são caracterizados como crimes de guerra de acordo com os arts. 8 (2), b, xxvi e 8 (2), e, vii, do Estatuto de Roma.

\footnotetext{
${ }^{25}$ É importante ter em vista que a República Democrática do Congo ratificou o Estatuto de Roma em 11 de abril de 2002.

${ }^{26}$ Interessante manifestação a respeito em BASSIOUNI, Cherif. The ICC: Quo Vadis? Journal of Internacional Criminal Justice, [S.1.], n. 4, p. 425, 2006, ressaltando que o encaminhamento de Lubanga ao TPI é de grande significância.

${ }^{27}$ Conforme WEIGEND, Thomas. Intent, mistake of law and co-perpetration in the Lubanga Decision on Confirmation of Charges. Journal of International Criminal Justice, [S.1.], n. 6, p. 472, 2008, Lubanga foi fundador e líder da União Patriótica Congolesa, um grupo político ativo desde 2000, em Ituri, uma província da República Democrática do Congo, que tinha base em um grupo étnico local, Hema, e recebia auxílio oficial de Ruanda.
} 
A Câmara confirmou tais acusações contra Lubanga ${ }^{28}$, constatando a existência de fundamentos suficientes para crer que o acusado é penalmente responsável como coautor dos fatos objeto das três acusações apresentadas pelo Ministério Público, os quais ocorreram no início de setembro de 2002, quando foram fundadas as Force Patriotiques pour la Liberation du Congo, até 13 de agosto de 2003.

Com isso, a Corte anunciou publicamente, em 10 de fevereiro de 2006, que a Primeira Câmara de Questões Preliminares (Pre-Trial Chamber I) - composta no momento da decisão pela juíza Sylvia Steiner e Akua Kuenyehia e pelo juiz Claude Jorda - emitiu a primeira ordem de prisão contra Thomas Lubanga Dyilo, o qual, em 17 de março de 2006, foi detido e então transferido para Haia, na Holanda, e atualmente se encontra recolhido à prisão de Haaglanden, em Scheveningen. ${ }^{29}$

Por conseguinte, o caso foi remetido a julgamento perante a Primeira Câmara de Julgamento do TPI, composta pelos juízes Adrian Fulford, o presidente, a juíza Elizabeth Odio Benito e o juiz René Blattmann ${ }^{30}$.

E após quase sete anos da entrada em vigência do Estatuto de Roma, o Tribunal Penal Internacional começou o seu primeiro julgamento, mais precisamente, em 26 de janeiro de 2009.

Contudo, é oportuno referir ainda que, em 04 de março de 2009, a Primeira Câmara de Questões Preliminares decidiu pela decretação da prisão de Omar Hassan Ahmad Al Bashir, Presidente do Sudão, ante as fundadas acusações pela prática de crimes de guerra e crimes contra a humanidade, apresentadas pelo Ministério Público, ${ }^{31}$ o que é indicativo de que um segundo

${ }^{28}$ Ampla análise da decisão e seus fundamentos, com considerações críticas WEIGEND, Thomas. Intent, mistake of law and co-perpetration in the Lubanga Decision on Confirmation of Charges. Journal of International Criminal Justice, [S.1.], n. 6, p. 471-487, 2008.

${ }^{29}$ Compare CICC. Global Coalition says Court's first trial a Landmark opportunity for victims in new international judicial Order. New York, 2009. Disponível em:<http://www.iccnow. org/documents/CICC_PR_Lubanga_Trial_Opens_26_Januar.pdf $>$. Acesso em: 30 jan. 2009.

${ }^{30}$ Compare CICC. Opening of the first trial of the Court on Monday 26 January 2009. New York, 2009. Disponível em: <http://www.icc-cpi.int/press/pressreleases/467.html>. Acesso em: 30 jan. 2009.

${ }^{31}$ Compare CICC. ICC issues a warrant of arrest for Omar Al Bashir. New York, 2009. Disponível em:<http://www.icc-cpi.int/NR/exeres/0EF62173-05ED-403A-80C8-F15EE1D25BB3.htm>. Acesso em: 05 mar. 2009. 
caso, possivelmente, seja submetido a julgamento pela Corte. Isso porque Bashir é suspeito de ser criminalmente responsável, enquanto coautor indireto, pela prática de ataques intencionais diretos contra uma parte da população civil de Darfur, no Sudão, que resultaram em assassinato, extermínio, rapto, tortura e sequestro de uma grande quantidade de cidadãos e no saqueamento dos seus bens.

A entrada em funcionamento da Corte, com o encaminhamento dos primeiros casos a julgamento, de certo modo, reclama dos Estados-Partes uma posição no sentido de estarem aptos a promover a persecução dos crimes previstos no Estatuto, já no plano interno. Em vista disso, cumpre proceder à análise da situação no plano interno brasileiro.

\section{A implementação do estatuto de Roma no âmbito interno brasileiro}

Como visto, apesar de não haver uma obrigatoriedade de implementação do Estatuto de Roma no âmbito interno dos Estados (supra, 1), tal transposição faz-se necessária, sobretudo, em virtude do compromisso assumido e por força do princípio da complementariedade. E, justamente em razão disso e por razões de política internacional, inúmeros Estados-Partes já procederam à implementação, adequando o direito interno às regras do Estatuto (assim os exemplos do Canadá, Alemanha, França e Trinidad y Tobago - supra, item 2).

O Brasil, por sua vez, ratificou o texto do Estatuto de Roma por meio do Decreto Legislativo ${ }^{\circ} 112$, de 06 de junho de 2002, sendo que o depósito foi realizado em 20 de junho de 2002, tendo o Presidente da República promulgado o Estatuto de Roma, pelo Decreto ${ }^{\circ}$ 4388, de 25 de setembro de 2002. ${ }^{32}$

${ }^{32}$ Compare JAPIASSÚ, Carlos Eduardo Adriano. Possibilidades e desafios de adequação do Estatuto de Roma à Ordem Constitucional Brasileira, In: AMBOS, Kai; JAPIASSÚ, Carlos E. A. (Org.). Tribunal Penal Internacional. Rio de Janeiro: Lumen Juris, 2005. p. 200; veja, igualmente com uma ampla análise do projeto brasileiro, BADARÓ, Gustavo. O projeto de lei de adaptação da legislação brasileira ao Estatuto de Roma do Tribunal Penal Internacional: tramitação e questões constitucionais polêmicas. In: AMBOS, Kai; MALARINO, Ezequiel; WOISCHNIK, J. (Org.). Temas actuales del derecho penal internacional. Buenos Aires: Konrad Adenauer Stiftung, 2005. p. 62 et seq. 
Contudo, e frise-se, passados quase sete anos da entrada em vigor do Estatuto de Roma e, por sua vez acrescente-se, do respectivo depósito do instrumento de ratificação pelo governo brasileiro, diferentemente da Alemanha, Canadá, França e Trinidad y Tobago, o Brasil ainda não procedeu à implementação.

Os trabalhos dirigidos à implementação começaram pouco tempo depois da ratificação do Estatuto pelo Brasil, em 2002. No ano de 2004 foi criado um grupo de trabalho (formado por representantes do governo e da sociedade civil) para elaborar e discutir o projeto de lei de implementação, bem como para resolver eventuais questões que estivessem em conflito com a Constituição Federal. Em 23 de setembro de 2008, o projeto foi submetido à Câmara dos Deputados ${ }^{33}$ e, após aprovação nesta casa, deverá, ainda, ser remetido ao Senado Federal.

Entretanto, abstraindo a perspectiva histórica, é importante observar o fato de que a política exterior do Brasil no envolvimento com os direitos humanos começou a se intensificar a partir de 1992 com a adesão a tratados gerais de proteção, os dois da ONU e a convenção da OEA. E, em 1997, o Brasil reconheceu a jurisdição da Corte Interamericana de Direitos Humanos. Tais fatores têm sido apontados como representativos da preocupação do Brasil com os direitos humanos, de tal forma que levaram Cervo, ao fazer um balanço da Era Cardoso, a afirmar que "a criatividade política brasileira e sua expressão diplomática tiveram papel inovador na vinculação entre fruição de direitos humanos e condições de bem estar social alcançadas com o desenvolvimento econômico". ${ }^{34}$

Em face disso, e para que se possa levar adiante, aqui, a perspectiva crítica que se pretende, é importante, antes de tudo, ter em vista a indubitável natureza jurídica do Estatuto de Roma como tratado internacional de direitos humanos, com caráter protetivo. Pois bem, diante disso, é paradoxal e incompreensível que um Estado cujas relações políticas, sobretudo, internacionais, como o brasileiro,

\footnotetext{
${ }^{33}$ Atualmente o projeto, com número de referência 4038/2008, encontra-se com a Comissão de Constituição e Justiça e de Cidadania.

${ }^{34}$ CERVO, Amado Luiz. Relações internacionais do Brasil. Rev. Bras. Polít. Int., [S.1.], n. 45, v. 1, p. $5-35,2002$.
} 
que, aliás, tem acentuado sua preocupação e declarado seu interesse em contribuir com a proteção dos direitos humanos, não tenha primado pela celeridade na implementação do Estatuto de Roma. ${ }^{35}$

Moura, Zilli e Ghidalevich ressaltam o fato de que a ausência de implementação do Estatuto de Roma no ordenamento jurídico acaba levando à subsunção de determinados fatos a outros tipos penais, cujo campo de tutela originária não estava informado pela necessidade de proteção dos bens jurídicos mais caros à humanidade ${ }^{36}$. Por outro lado, Moura tem afirmado que "por suas características culturais, geográficas e históricas, as questões referentes ao Direito Penal Internacional não têm despertado grande atenção na sociedade civil, na comunidade acadêmica e nem nos meios oficiais, já que não há guerra interna ou externa no Brasil" ${ }^{37}$. Trata-se de um argumento limitado e, portanto, insubsistente, haja vista que leva em conta unicamente os crimes de guerra como objetos da tutela penal pelo Estatuto de Roma (sendo suficiente, para tanto, observar as tipificações relativas aos crimes contra a humanidade no Estatuto de Roma, como no Projeto de Lei de Implementação no Brasil). Isso, aliás, indubitavelmente gera um óbice à consolidação da ideia de um Direito Penal Internacional no âmbito interno.

Naturalmente, a demora na elaboração de um projeto de implementação do Estatuto para o plano interno brasileiro deve-se, primeiramente, tanto à questão constitucional, como infraconstitucional. Sob o ponto de vista constitucional, alguns preceitos do Estatuto prima facie bateriam de frente com preceitos da Constituição Federal (tais como aqueles relativos à entrega de nacionais ao TPI; à pena de prisão perpétua; às imunidades e prerrogativas de função; à reserva legal e ao

\footnotetext{
${ }^{35}$ Sobretudo em virtude de que, como já referido por Bitencourt, a integração do Estatuto de Roma ao nosso ordenamento jurídico encontra amparo nos parágrafos do art. $5 .^{\circ}$ da Constituição Federal, conforme BITENCOURT, Cezar Roberto. Tratado de direito penal: parte geral. São Paulo: Saraiva, 2009. v. 1. p. 205-206.

${ }^{36}$ MOURA, Maria Thereza R. de Assis; ZILLI, Marcos A. Coelho; GHIDALEVICH, Fabíola G. M. Informes Nacionales: Brasil. In: AMBOS, Kai; MALARINO, Ezequiel; ELSNER, Gisela (Org.). Jurisprudencia latinoamericana sobre derecho penal internacional. Berlin: Konrad Adenauer Stiftung, 2008. p. 125.

${ }^{37}$ Assim MOURA, Maria Thereza R. de Assis. Implementação do Estatuto de Roma na América Latina. AIDP, Rio de Janeiro, 2009. Disponível em: <http://www.aidpbrasil.org. br/>. Acesso em: 05 jan. 2009.
} 
respeito à coisa julgada $)^{38}$. Já no que diz respeito ao aspecto infraconstitucional, tem-se que a maior parte das normas incriminadoras (excetua-se o crime de genocídio que já estava tipificado em lei própria) e processuais ali esculpidas não possui correspondente no plano interno brasileiro, de forma que se optou por uma transposição completa, em caráter pontual (assim como Trinidad y Tobago).

Entretanto, a isto se deve agregar o grave problema, já ressaltado por Feldens, da insuficiência e letargia estatal brasileira e da necessidade de que se tome a sério a proteção efetiva dos direitos humanos fundamentais ${ }^{39} \mathrm{e}$, para isso, traz a lume o caso Damião Ximenes Lopes, portador de doença mental torturado até a morte, em estabelecimento destinado a tratamento psiquiátrico, localizado no município de Sobral/ $\mathrm{CE}$, cujo caso foi levado à Corte Interamericana de Direitos Humanos e resultou na condenação do Estado Brasileiro pela violação dos direitos à vida e à integridade pessoal, consagrados nos artigos 4.1, 5.1 e 5.2 da CADH e à obrigação geral de respeitar e garantir esses mesmos direitos, consagrados no art. 1.1 da mesma Convenção. Esse aspecto, aliás, é característico do Estado brasileiro, ou seja, da realidade avassaladora onde as violações aos direitos humanos se apresentam com não tão pouca frequência e parecem conflitar com a ideia apontada por Cervo, de "preocupação do Brasil com os direitos humanos" e de "vinculação entre fruição de direitos humanos e condições de bem estar social alcançadas com o desenvolvimento econômico”.

O Projeto de Lei no 4.038 de 2008 (Projeto de Lei de Implementação Brasileiro), que dispõe sobre o crime de genocídio, define os crimes contra a humanidade, os crimes de guerra e os crimes contra a administração da justiça do Tribunal Penal Internacional, institui normas processuais específicas, dispõe sobre a cooperação com o Tribunal Penal Internacional e dá outras providências, possui 131 dispositivos $^{40}$.

${ }^{38}$ Para uma análise aprofundada da questão veja MAZZUOLI, Valério de Oliveira. Curso de direito internacional público. São Paulo: RT, 2008. p. 847 et seq.

${ }^{39}$ Compare FELDENS, Luciano. De Damiens a Damião: deveres de proteção penal. In: GAUER, Ruth (Org.). Criminologia e sistemas jurídico-penais contemporâneos. Porto Alegre: EDIPUCRS, 2008. p. 436.

${ }^{40}$ BRASIL. Projeto de lei $n^{\circ} 4.038$ de 2008. Dispõe sobre o crime de genocídio, define os crimes contra a humanidade, os crimes de guerra e os crimes contra a administração da justiça do Tribunal Penal Internacional, institui normas processuais específicas, dispõe sobre a cooperação com o Tribunal Penal Internacional, e dá outras providências. Brasília, 2008. Disponível em: < http://www.planalto. gov.br/ccivil_03/projetos/PL/2008/msg700-080917.htm>. Acesso em: 05 jan. 2009. 
E particularmente em face do primeiro caso sub judice perante o Tribunal Penal Internacional - caso Lubanga - e as expectativas geradas no tocante à atuação da Corte e à repercussão em relação à decisão, é imperiosa uma maior celeridade no plano legislativo brasileiro no que diz respeito à implementação, cumprindo, assim, o compromisso assumido pelo país perante a comunidade internacional ${ }^{41}$, bem como, com isso, tornando possível o exercício primário da jurisdição pelo Estado Brasileiro.

\section{Conclusões}

A implementação do Estatuto de Roma pelos Estados-Partes resulta: (1) do compromisso assumido pelos Estados-Partes perante a comunidade internacional, conforme art. 10 do preâmbulo do Estatuto; (2) do exercício primário da jurisdição pelos próprios Estados-Partes, por força do princípio da complementariedade; (3) do dever de cooperação com o TPI, assumido pelos Estados-Partes; bem como (4) por questões de política internacional.

É digna de nota a atuação daqueles vários países que já procederam à implementação do Estatuto de Roma e de maneira extremamente célere (tal como Canadá, Alemanha e França, que optaram por uma implementação limitada e, principalmente, Trinidad y Tobago, que optou por uma implementação completa, em caráter pontual).

O Brasil, por sua vez, passados quase sete anos da ratificação do Estatuto de Roma, ainda não procedeu à implementação. Entretanto, o Projeto de Lei de Implementação, já concluído, foi remetido, em setembro de 2008, primeiramente à Câmara dos Deputados que, após, deverá remetê-lo ao Senado Federal.

\footnotetext{
${ }^{41}$ Tal compromisso, aliás, foi ressaltado pelo Presidente da Republica do Brasil em sua mensagem de encaminhamento do Projeto de Lei de Implementação ao Congresso Nacional: "Desse modo, com o intuito de incorporar o Estatuto de Roma ao ordenamento jurídico nacional, e assim dar cumprimento ao compromisso internacional assumido pelo Estado brasileiro, a Secretaria Especial dos Direitos Humanos da Presidência da República instituiu, sob sua coordenação, Grupo de Trabalho (GT) que resultou na elaboração do Projeto de Lei que 'dispõe sobre o crime de genocídio, define os crimes contra a humanidade, crimes de guerra e crimes contra a administração da justiça do Tribunal Penal Internacional, institui normas processuais específicas, dispõe sobre a cooperação com o Tribunal Penal Internacional e dá outras providências."'
} 
É crível que já a conclusão do Projeto de Lei de Implementação brasileiro de per se representa um grande passo em direção ao cumprimento do compromisso assumido pelo país com a subscrição e posterior ratificação do Estatuto. Porém, espera-se que o Poder Legislativo proceda com maior celeridade a fim de, com isso, tornar possível o exercício primário da jurisdição pelo Estado brasileiro, posto que o Brasil estará, assim, manifestando seu real interesse em promover a cooperação com o TPI e cumprindo seu compromisso assumido perante a comunidade internacional.

\section{The Implementation of the Rome Statute in Brazilian domestic context before the recent movements in the International Criminal Court}

\section{Abstract}

This article examines the implementation of the Rome Statute under Brazilian domestic in the context of the recent movements in the International Criminal Court. Thus, using a phenomenological method, under which seeks to follow from theory to practice to examine, especially of critical mode, the issue about the implementation of the Rome Statute in Brazil. In view of this, is analyzed, first, the requirement to implement the Rome Statute and its legal and politics bases. Secondly, it provides some examples of efforts towards implementing the Statute and analyzes the fact that the first case has already been sent for trial by the Court. Thirdly, it discusses some aspects of the implementation in Brazil and the need of more celerity in this procedure. From the study developed, it is observed that almost seven years after the ratification of the Rome Statute, Brazil has not made its implementation, but nevertheless produced a Draft of implementing Legislation, expressing their genuine interest in promoting cooperation with the Court and comply their commitment to the international community.

Keywords: Rome Statute. International Criminal Court. Implementation in Brazil. 


\section{Referências}

AMBOS, Kai. Internationales strafrecht, strafanwendungsrecht, völkerstrafrecht, europäisches strafrecht. München: Beck, 2006.

AMBOS, Kai. La implementación del Estatuto de la Corte Penal Internacional en Alemania. Revista Electrónica de Ciencia Penal y Criminologia, [S.1.], n. 7, p. 1-31, 2005.

AMBOS, Kai; JAPIASSÚ, Carlos E. A. (Org.). Tribunal Penal Internacional. Rio de Janeiro: Lumen Juris, 2005.

AMBOS, Kai; MALARINO, Ezequiel; ELSNER, Gisela. Jurisprudencia latinoamericana sobre derecho penal internacional. Berlin: Konrad Adenauer Stifung, 2008.

AMBOS, Kai; MALARINO, Ezequiel; WOISCHNIK, Jan. Temas actuales del derecho penal internacional. Buenos Aires: Konrad Adenauer Stifung, 2005.

BASSIOUNI, Cherif. The ICC: Quo Vadis? Journal of Internacional Criminal Justice, [S.1.], n. 4, p. 425, 2006.

BITENCOURT, Cezar Roberto. Tratado de direito penal: parte geral. São Paulo: Saraiva, 2009. v. 1.

BRASIL. Projeto de lei $n^{\circ} 4.038$ de 2008. Dispõe sobre o crime de genocídio, define os crimes contra a humanidade, os crimes de guerra e os crimes contra a administração da justiça do Tribunal Penal Internacional, institui normas processuais específicas, dispõe sobre a cooperação com o Tribunal Penal Internacional, e dá outras providências. Brasília, 2008. Disponível em: <http:// www.planalto.gov.br/ccivil_03/projetos/PL/2008/msg700-080917.htm>. Acesso em: 05 jan. 2009.

CANADÁ. Crimes against humanity and war crimes act. Ottawa, 2000. Disponível em: <http://laws.justice.gc.ca/PDF/Statute/C/C-45.9.pdf >. Acesso em: 01 fev. 2009.

CASSESE, Antonio. The statute of the International Criminal Court: some preliminary reflections. European Journal of International Law, [S.l.], n. 10, 1999.

CERVO, Amado Luiz. Relações internacionais do Brasil. Rev. Bras. Polít. Int., [S.l.], n. 45 , v. 1, p. 5-35, 2002. 
FELDENS, Luciano. De Damiens a Damião: deveres de proteção penal. In: GAUER, Ruth (Org.). Criminologia e sistemas jurídico-penais contemporâneos. Porto Alegre: EDIPUCRS, 2008.

FRANÇA. Loi no 2002-268 du 26 février 2002 relative à la coopération avec la Cour pénale international. Paris, 2002. Disponível em: <http://www.iccnow.org/ documents/FrenchImplementing Leg.pdf>. Acesso em: 01 fev. 2009.

GEIGER, Hansjörg. Internationaler Strafgerichtshof und Aspekte eines neuen Völkerstrafgesetzbuches. In: [S.l.:s.n.], 2002. . Freundesgabe für Alfred Büllesbach.

KAUL, Hans-Peter. La Corte Penal Internacional. Diálogo Político, [S.l.], n. 3, p. 21, set. 2004.

KRESS, Claus. Versailles, Nuremberg: the Hague, Germany and International Criminal Law. The International Lawyer, [S.1.], v. 40, n. 1, p. 39, 2006.

LÜDERS, Strafgerichtsbarkeit über Angehörige des Feindstaats. Süddeutsche Juristen Zeitung, v. 1, n. 8/9, p. 214 passim, 1946.

MAX-PLANCK-INSTITUT FÜR AUSLÄNDISCHES UND INTERNATIONALES STRAFRECHT. Freiburg, 2009. Disponível em: <http://www.mpicc.de/ww/de/ pub/forschung/publikationen/ onlinepub.htm>. Acesso em: 30 jan. 2009.

MAZZUOLI, Valério de Oliveira. Curso de direito internacional público. São Paulo: RT, 2008.

MOURA, Maria Thereza R. de Assis. Implementação do Estatuto de Roma na América Latina. AIDP, Rio de Janeiro, 2009. Disponível em: <http://www. aidpbrasil.org.br/>. Acesso em: 05 jan. 2009.

MOURA, Maria Thereza R. de Assis; ZILLI, Marcos A. Coelho; GHIDALEVICH, Fabíola G. M. Informes Nacionales: Brasil. In: AMBOS, Kai; MALARINO, Ezequiel; ELSNER, Gisela (Org.). Jurisprudencia latinoamericana sobre derecho penal internacional. Berlin: Konrad Adenauer Stiftung, 2008. p. 125.

SCHABAS, William. A canadian implementing legislation for the Rome Statute. Yearbook of International Humanitarian Law, Cambridge, v. 3, p. 337, 2000.

SCHABAS, William. An introduction to the international criminal court. Cambridge: Cambridge University, 2001. 
SILVA, Pablo Rodrigo Alflen da (Org.). Tribunal Penal Internacional: aspectos fundamentais e o novo código penal internacional alemão. Porto Alegre: S. A. Fabris, 2004.

TAVERNIER, Paul. Comment surmonter les obstacles constitutionnels à la ratification du Statut de Rome de la Cour Pénale Internationale. Revue Trimestrielle des Droits de L'Homme, Paris, n. 51, p. 545 et. seq., jul. 2002.

WEIGEND, Thomas. Intent, mistake of law and co-perpetration in the Lubanga Decision on Confirmation of Charges. Journal of International Criminal Justice, [S.l.], n. 6, p. 472, 2008.

WERLE, Gerhard; JEßBERGER, Florian. Das Völkerstrafgesetzbuch. Juristenzeitung, n. 15/16, p. 725, 2002.

WIRTH, Steffen. Germany's new international crimes code. Journal of International Criminal Justice, [S.1.], n. 1, p. 153 passim, 2003.

YANG, Lijun. On the principle of complementarity in the Rome Statute of the International Criminal Court. Chinese Journal of International Law, [S.l.], v. 4, p. 121-132, 2005. 